\title{
Obesity and risk of job disability in male firefighters
}

\section{Citation}

Soteriades, E. S., R. Hauser, I. Kawachi, D. C. Christiani, and S. N. Kales. 2008. "Obesity and Risk of Job Disability in Male Firefighters." Occupational Medicine 58 (4): 245-50. https:// doi.org/10.1093/occmed/kqm153.

\section{Permanent link}

http://nrs.harvard.edu/urn-3:HUL.InstRepos:41288155

\section{Terms of Use}

This article was downloaded from Harvard University's DASH repository, WARNING: This file should NOT have been available for downloading from Harvard University's DASH repository.

\section{Share Your Story}

The Harvard community has made this article openly available.

Please share how this access benefits you. Submit a story.

\section{Accessibility}




\title{
Obesity and risk of job disability in male firefighters
}

\author{
Elpidoforos S. Soteriades ${ }^{1}$, Russ Hauser ${ }^{1}$, Ichiro Kawachi ${ }^{2}$, David C. Christiani ${ }^{1,3}$ and \\ Stefanos N. Kales ${ }^{1,4}$
}

Background Obesity is a major public health problem and a workplace epidemic in Western societies. However, little is known about the association between obesity and job disability in specific occupational groups.

Aim To examine the association between obesity and risk of job disability among firefighters.

Methods A prospective cohort study design was employed in following 358 Massachusetts firefighters enrolled in a statewide medical surveillance program. We prospectively evaluated time to development of adverse employment outcomes $>6$ years of follow-up.

Results In multivariable-adjusted Cox proportional hazard models, we found that every one-unit increase in body mass index (BMI) was associated with a 5\% increased risk of job disability. Compared to firefighters in the lowest tertile of BMI (BMI < 27.2), those in the highest tertile $(\mathrm{BMI} \geq 30.2)$ had a significantly increased risk of an adverse employment event with a multivariable-adjusted hazard ratio (HR) of 1.98 (95\% CI 1.06-3.72). There was also a significant dose-response relationship of increasing risk across tertiles, as well as a significant trend: HR 1.39 (95\% CI 1.04-1.86). The highest categories of $\mathrm{BMI}$ had a $60-90 \%$ increased risk of job disability compared to the lowest or normal-weight categories, respectively.

Conclusions Obesity is associated with higher risk of job disability in firefighters. Additional research is needed to further explore our findings. Our study may have economic and public health implications in other occupational settings.

Key words BMI; firefighters; fitness for duty; job disability; obesity.

\section{Introduction}

Obesity has become a major public health problem, affecting men and women of all ages and racial/ethnic groups [1]. Numerous studies have shown strong and consistent positive associations between being overweight or obese with several adverse health outcomes including hypertension, dyslipidemia, diabetes, cardiovascular

${ }^{1}$ Harvard School of Public Health, Department of Environmental Health, Environmental and Occupational Medicine and Epidemiology (EOME), Boston, MA, USA.

${ }^{2}$ Harvard School of Public Health, Departments of Epidemiology and Society, Human Development and Health, Boston, MA, USA.

${ }^{3}$ Massachusetts General Hospital, Pulmonary/Critical Care Unit, Harvard Medical School, Boston, MA, USA.

${ }^{4}$ The Cambridge Health Alliance, Harvard Medical School, Employee Health and Industrial Medicine, Cambridge, MA, USA.

Correspondence to: Elpidoforos S. Soteriades, 2 Antigonis Street, 2035 Strovolos, Nicosia, Cyprus. Tel: +357 99 410677; fax: +357 22316915;

e-mail: esoteria@hsph.harvard.edu disease, cancer, and a number of other morbid conditions as well as mortality [2,3]. Many previous studies have also estimated the health care costs associated with obesity [4], the costs of increased body mass index (BMI) in the workplace [5] and the costs of obesity to the society as a whole [6]. Data, however, on the association between obesity and other occupational outcomes are limited. For example, a limited number of studies have looked at the association of obesity and work performance [7], workers' compensation claims [8], job absenteeism [9], early retirement [10], locomotive and other disability [11], lost productive time (LPT) [12] and short- or long-term disability among employees in different occupational settings [13-15]. In particular, to our knowledge, there are no previous studies examining the association of obesity with the risk of job disability in firefighters.

Firefighters are expected to perform difficult manual tasks with high-energy expenditure on short notice, in cases of emergency. Obesity may jeopardize firefighters' performance and have deleterious effects on their health 
and/or public safety [16]. The National Fire Protection Association (NFPA) publishes recommendations for baseline and periodic fitness for duty evaluations, in order to ensure adequate job performance for firefighters. However, current NFPA guidelines do not even consider extreme obesity (Class III) as a disqualifying condition with respect to fitness for duty [17]. In addition, the current NFPA Standard on Health-Related Fitness Programs for Firefighters does not provide specific BMI target levels [18].

To evaluate the association between overweight and obesity and the risk of job disability, we prospectively examined a cohort of US male firefighters $>6$ years of follow-up.

\section{Methods}

The study was initiated in 1996 when an open cohort of 340 firefighters from six regional hazardous materials teams in the Commonwealth of Massachusetts underwent a baseline medical examination in the context of a statewide medical surveillance program. Twenty-five additional firefighters were enrolled during the followup period. Approximately, $75 \%$ of the cohort was comprised of hazardous materials technicians and the remaining were support members. The firefighters joined the hazardous materials teams on a contractual basis in addition to their primary occupational duties as municipal firefighters in local fire departments throughout the State of Massachusetts.

Only four female firefighters were enrolled and were excluded from further statistical analyses. Thirty-two male firefighters were also excluded because baseline BMI or other covariables used in the multivariableadjusted models were missing, if they had no follow-up or they were diagnosed with any of the outcomes of interest at baseline. Additional methodological information is described elsewhere [19]. The Institutional Review Boards of the Harvard School of Public Health, the Cambridge Health Alliance and the Northeast Specialty Hospital approved the study.

At baseline and each follow-up examination, firefighters underwent weight and height measurements. $\mathrm{BMI}$ was calculated using the formula: $\mathrm{BMI}=703.1 \times$ (weight in pounds)/(height in inches) ${ }^{2}$. The firefighters were assigned to different BMI categories based on the current guidelines of the National Heart Lung and Blood Institute (NHLBI) Obesity Education Initiative [20]. Classes I, II and III (extreme) obesity were defined as a BMI between 30 and 34.9 ( $30 \leq \mathrm{BMI}<34.9$ ), 35 and 39.9 ( $35 \leq \mathrm{BMI}<39.9)$ and $\geq 40(\mathrm{BMI} \geq 40)$, respectively. In addition, we used dichotomous measures of excess weight using different cutoff points of BMI such as the mean and the median. Categorical measures of obesity were based either on the current guidelines of the NHLBI Obesity Education Initiative (as defined above) or on the distribution of BMI in our study sample (cohort tertiles or quartiles).

Prospective information on several other factors was also routinely collected at every examination and entered into the computerized repository. Baseline and follow-up measurements included age, sex, job type (technician, support member), smoking history, blood pressure, blood glucose, total cholesterol and others.

The firefighters were followed for a maximum of 6 years until the end of follow-up (31 August 2002). All changes in the employment status of firefighters with respect to short-term or permanent job disability (placement on 'injured on-duty' status, termination of duty, resignation, premature retirement or death) were verified by the Massachusetts' Office of Hazardous Materials Response. In addition, information on incident cardiovascular disease events (new myocardial infarction, incident coronary heart disease or significant arrhythmia potentially interfering with duty) was collected by systematically reviewing the firefighters' medical examination summaries. Time to development of a job disability event was considered as our primary outcome of interest.

Statistical analyses were performed using SAS software (version 6.12). $t$-test, chi-square test and analysis of variance were used to compare differences in standard cardiovascular disease risk factors between different BMI categories. Person-years of follow-up were calculated from the baseline examination until the end of the study or a firefighter's follow-up period. Individual follow-up periods, for each firefighter, were calculated up until the end of the study or until a firefighter was found medically unfit for duty at the time of each annual index examination. Age- and multivariable-adjusted Cox proportional hazard regression models (adjusted for age, smoking status, hypertension, systolic and diastolic blood pressure, total cholesterol, diabetes and job type) were used to evaluate the association between different BMI categories and the development of job disability.

We used different threshold and trend models in order to examine dose-response relationships between the different levels of obesity and our outcome of interest. Different categorical measures of BMI were also used to determine the shape of a possible relationship between $\mathrm{BMI}$ and job disability. Finally, we evaluated potential reverse causation of the above association (i.e. predisposing factors or disease causing job disability leading to lower or higher BMI) with a time-lag model excluding those who developed any of the outcomes of interest in the first year of follow-up. The level of significance for all analyses was considered at 0.05 and was two sided for all tests.

\section{Results}

Of the 340 firefighters initially examined at baseline, 329 $(97 \%)$ met all inclusion criteria. The cohort increased to 
358 from additionally enrolled firefighters at follow-up. The firefighters were followed for an average of 5.3 years (range 0.3-6.5 years) with a total of 1813 person-years of follow-up. At baseline, the average age was $39.2 \pm 7$ years (range 20-58 years), and the average BMI was $29.0 \pm 4$ (range 19.3-44.7). Twenty seven percent of firefighters had Class I obesity, $7 \%$ had Class II obesity and $0.6 \%$ had Class III, extreme, obesity, respectively. Baseline characteristics of the cohort by BMI category are summarized in Table 1. Obese firefighters were more likely to have hypertension compared to overweight or normal-weight firefighters.

During 6 years of follow-up, 76 firefighters $(23 \%)$ experienced a job disability event resulting in lost time: 21 experienced an injury while on duty, 8 were terminated and 2 were removed from active duty, 38 resigned prematurely and 4 retired prematurely, 2 developed cardiovascular events and one died while on duty. In 16 of the above cases, the firefighter eventually received a permanent disability retirement pension. The incidence rate of job disability was $42.8,35.1$ and 53.5 per 1000 personyears, while the observed 6-year cumulative incidence of job disability was 26,21 and $32 \%$ in normal weight, overweight and obese firefighters, respectively.

Several different dichotomous BMI measures showed that firefighters in the highest BMI category had a $50-70 \%$ increased risk of job disability (data not shown). In particular, firefighters above the median of the BMI distribution (28.5) in our sample had a $70 \%$ significantly increased risk of job disability compared to those below the median (hazard ratio $[\mathrm{HR}]=1.69$, 95\% CI 1.02-2.80).
In Table 2, we present the results of several different age- and multivariable-adjusted Cox proportional hazard regression models. Examining continuous BMI, we found that for every one-unit increase, there was a suggestion $(P<0.10)$ of a $5 \%$ increased risk of job disability: HR 1.05 (95\% CI 0.99-1.11). Using different categorical measures of BMI, significant associations were identified among both tertiles and quartiles of the BMI distribution. For example, compared to firefighters in the lowest tertile of BMI (BMI <27.2), those in the highest tertile $(\mathrm{BMI} \geq 30.2)$ had a significantly increased risk of an adverse employment event with a multivariable-adjusted HR of 1.98 (95\% CI 1.06-3.72). There was also a significant dose-response relationship of increasing risk across tertiles, while the trend across tertiles was significantly increased: HR 1.39 (95\% CI 1.04-1.86).

For all measures, we consistently observed increasing risk of adverse employment events with increasing BMI, especially in the obese range. Although mild overweight appeared slightly protective, the latter results were not statistically significant. However, this may suggest a J-shape relationship with the risk of job disability. Examination of reverse causation using a time-lag model (excluding firefighters who developed any job disability event in the first year of follow-up) showed similar increasing risks, although not significant, while the suggestion of a J-shape relationship persisted. For example, using the four-category BMI, we found that compared to normal-weight firefighters, overweight firefighters had a lower risk [HR (95\% CI): $0.83(0.31-2.25)$ ], while there was no risk for Class I obesity [HR (95\% CI): 1.03 (0.35-3.00)] and a suggestion of increased risk for

Table 1. Characteristics of the cohort of firefighters according to BMI categories at baseline ${ }^{\mathrm{a}}$

\begin{tabular}{|c|c|c|c|c|}
\hline \multirow[t]{2}{*}{ Characteristic } & \multicolumn{3}{|l|}{ BMI } & \multirow[t]{2}{*}{$P$-value } \\
\hline & Normal, BMI $<25$ & Overweight, $25 \leq \mathrm{BMI}<30$ & Obese, $\mathrm{BMI} \geq 30$ & \\
\hline Total number- $n(\%)$ & $40(12)$ & $175(53)$ & $114(35)$ & \\
\hline Mean age-years $( \pm S D)$ & $37.3(7.3)$ & $39.4(6.9)$ & $39.8(6.7)$ & \\
\hline Mean SBP-mm Hg $( \pm S D)^{b}$ & $116.5(9.7)$ & $122.2(12.6)$ & $125.8(14.8)$ & \\
\hline Mean DBP-mm Hg $( \pm S D)^{b}$ & $75.7(8.1)$ & $78.9(8.7)$ & $80.8(10.3)$ & \\
\hline Age $\geq 40$ years $-n(\%)$ & $14(35)$ & $89(51)$ & $60(53)$ & 0.14 \\
\hline Smoking- $n(\%)$ & $6(15)$ & $19(11)$ & $12(11)$ & 0.72 \\
\hline Hypertension ${ }^{\mathrm{c}}-n(\%)$ & $0(0)$ & $31(18)$ & $29(25)$ & $<0.01$ \\
\hline \multicolumn{5}{|l|}{ High cholesterol- $n(\%)$} \\
\hline Total cholesterol $\geq 5.18 \mathrm{mmol} / 1$ & $23(58)$ & $120(69)$ & $83(73)$ & 0.20 \\
\hline \multicolumn{5}{|l|}{ High triglycerides-n $(\%)$} \\
\hline Triglycerides $\geq 2.26 \mathrm{mmol} / 1$ & $3(8)$ & $32(18)$ & $26(23)$ & 0.10 \\
\hline \multicolumn{5}{|l|}{ High blood glucose $-n(\%)$} \\
\hline Glucose $\geq 6.99 \mathrm{mmol} / 1$ & $0(0)$ & $2(1)$ & $2(2)$ & 0.68 \\
\hline
\end{tabular}

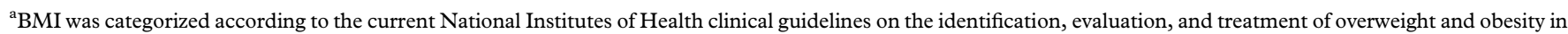
adults.

${ }^{\mathrm{b}} \mathrm{SBP}$ denotes systolic blood pressure and DBP denotes diastolic blood pressure.

${ }^{\mathrm{c}}$ Hypertension was defined as a systolic blood pressure of $\geq 140 \mathrm{~mm} \mathrm{Hg}$ and a diastolic blood pressure of $\geq 90 \mathrm{~mm} \mathrm{Hg}$. 
Table 2. Age- and multivariable-adjusted HRs (95\% CI) for the association of different categorical measures of BMI with job disability in male firefighters

\begin{tabular}{|c|c|c|}
\hline \multirow[t]{2}{*}{ BMI } & \multicolumn{2}{|c|}{ Job disability-HRs $(95 \% \mathrm{CI})$} \\
\hline & Age adjusted & $\begin{array}{l}\text { Multivariable } \\
\text { adjusted }^{\mathrm{a}}\end{array}$ \\
\hline Continuous BMI & $1.05(0.99-1.11)^{\mathrm{c}}$ & $1.05(0.99-1.11)^{\mathrm{c}}$ \\
\hline \multicolumn{3}{|l|}{$\begin{array}{l}\text { Categorical } \\
\text { (three categories) }\end{array}$} \\
\hline $\begin{array}{l}\mathrm{BMI}<25 \\
\quad(\text { reference })\end{array}$ & 1.00 & 1.00 \\
\hline $25 \leq \mathrm{BMI}<30$ & $0.80(0.38-1.68)$ & $0.81(0.37-1.78)$ \\
\hline $\mathrm{BMI} \geq 30$ & $1.26(0.60-2.65)$ & $1.26(0.56-2.83)$ \\
\hline Trend model & $1.26(0.87-1.82)$ & $1.27(0.85-1.88)$ \\
\hline \multicolumn{3}{|l|}{ Categorical (tertiles) } \\
\hline $\begin{array}{l}\mathrm{BMI}<27.2 \\
\quad(\text { reference })\end{array}$ & 1.00 & 1.00 \\
\hline $27.2 \leq \mathrm{BMI}<30.2$ & $1.38(0.74-2.58)$ & $1.39(0.72-2.69)$ \\
\hline $\mathrm{BMI} \geq 30.2$ & $1.94(1.08-3.49)^{\mathrm{b}}$ & $1.98(1.06-3.72)^{\mathrm{b}}$ \\
\hline Trend model & $1.39(1.04-1.86)^{\mathrm{b}}$ & $1.41(1.03-1.92)^{\mathrm{b}}$ \\
\hline \multicolumn{3}{|l|}{$\begin{array}{l}\text { Categorical } \\
\text { (four categories) }\end{array}$} \\
\hline $\mathrm{BMI}<25$ & 1.00 & 1.00 \\
\hline $25 \leq \mathrm{BMI}<30$ & $0.80(0.38-1.68)$ & $0.80(0.36-1.78)$ \\
\hline $30 \leq \mathrm{BMI}<35$ & $1.14(0.52-2.49)$ & $1.17(0.51-2.71)$ \\
\hline $\mathrm{BMI} \geq 35$ & $1.67(0.66-4.21)$ & $1.56(0.57-4.26)$ \\
\hline Trend model & $1.27(0.95-1.69)^{\mathrm{d}}$ & $1.25(0.92-1.70)^{\mathrm{d}}$ \\
\hline \multicolumn{3}{|l|}{ Categorical (quartiles) } \\
\hline $\mathrm{BMI}<26.3$ & 1.00 & 1.00 \\
\hline $26.3 \leq \mathrm{BMI}<28.4$ & $0.88(0.42-1.86)$ & $0.74(0.33-1.67)$ \\
\hline $28.4 \leq \mathrm{BMI}<31.4$ & $1.20(0.61-2.37)$ & $1.29(0.63-2.62)$ \\
\hline $\mathrm{BMI} \geq 31.4$ & $1.82(0.96-3.46)^{\mathrm{c}}$ & $1.70(0.85-3.37)^{\mathrm{d}}$ \\
\hline Trend model & $1.25(1.01-1.55)^{\mathrm{b}}$ & $1.26(1.00-1.58)^{\mathrm{b}}$ \\
\hline
\end{tabular}

aAdjusted for age (continuous), smoking (dichotomous), hypertension (dichotomous), systolic blood pressure (continuous), diastolic blood pressure (continuous), total cholesterol (continuous), diabetes (dichotomous) and job type (technician versus support member).

${ }^{\mathrm{b}} \mathrm{P}<0.05$

${ }^{\mathrm{c}} 0.05<P \leq 0.10$.

${ }^{\mathrm{d}} 0.10<P \leq 0.15$.

Classes II and III obesity combined [HR (95\% CI): 1.46 (0.41-5.19)]

\section{Discussion}

The results of our prospective cohort study show that male firefighters with obesity are more likely to develop job disability over time. In multivariable-adjusted Cox proportional hazard regression models, one-unit increase in BMI was associated with $5 \%$ increase in the risk of job disability, while obese firefighters in the highest tertile of BMI (BMI $\geq 30.2$ ) were two times (98\%) more likely to experience an adverse employment event than their colleagues in the lowest BMI tertile $(\mathrm{BMI}<27.2)$ after adjustment for potential confounders. There was also a significant dose-response relationship of increasing risk of adverse event across tertiles. We also found suggestive evidence of the examined association having a J-shape relationship, with the lowest risk identified among mildly overweight firefighters (BMI 25-27.1).

Our results in US firefighters are in general agreement with previous studies demonstrating that obesity is associated with lower work performance [7], higher work limitations, higher workers' compensation claims [8], disability retirement and disability pension and mortality $[3,10,11]$. Furthermore, in a recent report on the shortterm disability in the workplace, Arena et al. [15] showed a positive association with obesity, while those being overweight, had the shortest mean duration of short-term disability. In addition, Ricci and Chee [12] reported that obese workers were significantly more likely to report LPT, while overweight workers had the lowest reported LPT in the study. Our results are similar to the latter studies providing suggestive evidence of a J-shape relationship between BMI and risk of job disability. Also, the range of BMI with the lowest risk in our study ( 25 and 28.5) is similar to that of Mansson et al. [14]. It is unclear whether our findings are affected by the limitations of BMI as a measure of adiposity, especially among firefighters with increased muscle mass. On the other hand, they may truly support a non-linear relationship representing a true underlying association.

Several additional lines of evidence also support our findings, including the clustering of major cardiovascular disease risk factors associated with obesity as indicated in a previous study using the same cohort $[16,19]$ : the lower cardiorespiratory fitness of obese individuals and its associated risks [21], the risk of job disability associated with high blood pressure [22] and the risk of disability associated with heavy physical work [23]. Perhaps there exists a threshold balance between muscle mass and adiposity that is represented by a higher than normal $\mathrm{BMI}$ and fitness, as previously suggested for other male cohorts [24]. Our findings suggest that firefighters with BMI between 25 and 28.5 had the lowest risk of job disability. Above average muscle mass may provide an advantage to firefighters, taking into account the increased workload of their duties including rescue operations and fire suppression [25].

Strengths of our study include the originality of examined associations in firefighters, the prospective follow-up, the external verification of outcomes by the Massachusetts' Public Employee Retirement Administration Commission and the use of several statistical techniques to evaluate the robustness of our results. We would like, however, to also acknowledge several limitations. First, there may have existed different practices in the measurement of height and weight since the annual examinations and data collection processes were conducted in three different hospitals. There was no evidence, however, of 
systematic bias in the estimation of BMI among the three examination centers. Even if there were significant differences between the hospitals in the measurement of BMI, the misclassification of our exposure, which is not expected to be associated with the outcome events, most likely should have diluted the observed associations between obesity and job disability. Second, BMI is based on the weight-to-height ratio and does not distinguish between lean and adipose body mass. Therefore, it may be argued that current BMI guidelines would not apply to firefighters, who may have excess muscle mass. However, the chances of categorizing lean, highly muscular firefighters among obese compared to overweight subjects, is rather unlikely. Moreover, BMI has been shown to highly correlate with body fat percentage and fat mass, especially with increasing age due to this latter variable's associated decreases in lean body mass [26].

Furthermore, our study sample was relatively small, requiring that we use a summary outcome measure of different adverse employment events. However, we believe that this outcome accurately reflects firefighters who fail to meet fitness for duty criteria, and thus, may be generalizable to other public safety occupational settings. First, we excluded firefighters who resigned due to promotion to higher rank and would be unlikely to have health problems. Second, current evidence suggests that firefighters, who retire or resign under the age of 60, most likely do so due to health reasons [27]. Likewise, termination of duty is likely to occur due to lack of compliance with the medical examination process, which again may be associated with health-related problems. Therefore, all outcome events included in our study would lead to periods of job disability that interrupt active firefighting duty and lead to increased workplace health care and other costs.

In summary, we believe that our results provide evidence associating obesity with job disability in firefighters. Should our study be replicated in other occupational settings, it may have significant economic and public health implications for occupational groups such as the military, emergency medical service personnel and law enforcement officers. We believe that our findings support the need to improve health promotion in the fire service [28]. For example, appropriate diet and exercise programmes aimed at firefighters in the worksite should be supported. Given that coronary heart disease accounts for $\sim 40 \%$ of on-duty deaths among firefighters, the underlying cardiovascular disease risk factors are clustered with and aggravated by obesity; and firefighters' highest period of risk is during strenuous duties, there are additional urgent reasons to vigorously address obesity in the fire service [29]. In addition, occupational and primary care physicians, who provide care to firefighters, should be more assertive regarding weight counseling [30]. Finally, we believe that policy makers and fire department administrators should seriously consider our study results with respect to fitness for duty criteria on obesity for firefighters.

\section{Funding}

The National Institute of Occupational Safety and Health (OH03729) to S.N.K.; the National Institute of Environmental Health Sciences (ES00002) to D.C.C.

\section{Key points}

- Our study provides evidence of an association between obesity and the risk of job disability in firefighters, suggesting a J-shape relationship, with mildly overweight firefighters experiencing the lowest risk. Should our study be replicated in other occupational settings, it may have significant economic and public health implications for occupational groups such as the military, emergency medical service personnel, and law enforcement officers.

- The observed association supports the need to improve health promotion programmes in the fire service. In addition, occupational and primary care physicians, who provide care to firefighters, should be more assertive regarding weight counselling.

- Policy makers and fire chiefs should seriously consider our study results with respect to fitness for duty criteria on obesity for firefighters.

\section{Acknowledgements}

The authors would like to thank the firefighters-members of the Massachusetts District Hazardous Materials Response Teams and the staff of the Massachusetts Hazardous Materials Response Program. We would also like to offer our appreciation to the Massachusetts Public Employee Retirement Administration Commission, to Mrs Karen Cassidy (Northeast Specialty Hospital) and to the staff of all three Examination Centers for their cooperation and support for this project. Finally, we thank Antonios Tsismenakis for his assistance with proof reading and logistical handling of the manuscript.

\section{Conflicts of interest}

Dr Stefanos N. Kales and Dr David C. Christiani report having served as a paid expert witness and/or independent medical examiner in workers' compensation and disability cases, including cases involving firefighters.

\section{References}

1. Mokdad AH, Serdula MK, Dietz WH, Bowman BA, Marks JS, Koplan JP. The spread of the obesity epidemic in the United States, 1991-1998. F Am Med Assoc 1999; 282:1519-1522. 
2. Must A, Spadano J, Coakley EH, Field AE, Colditz G, Dietz WH. The disease burden associated with overweight and obesity. F Am Med Assoc 1999;282:1523-1529.

3. Fontaine KR, Redden DT, Wang C, Westfall AO, Allison DB. Years of life lost due to obesity. F Am Med Assoc 2003;289: 187-193.

4. Allison DB, Zannolli R, Narayan KM. The direct health care costs of obesity in the United States. Am $\mathcal{F}$ Public Health 1999;89:1194-1199.

5. Schmier JK, Jones ML, Halpern MT. Cost of obesity in the workplace. Scand $\mathcal{F}$ Work Environ Health 2006;32:5-11.

6. Wolf AM, Colditz GA. Current estimates of the economic cost of obesity in the United States. Obes Res 1998;6: 97-106.

7. Pronk NP, Martinson B, Kessler RC, Beck AL, Simon GE, Wang $\mathrm{P}$. The association between work performance and physical activity, cardiorespiratory fitness, and obesity. f Occup Environ Med 2004;46:19-25.

8. Ostbye T, Dement JM, Krause KM. Obesity and workers' compensation: results from the Duke health and safety surveillance system. Arch Intern Med 2007;167:766-773.

9. Bungum T, Satterwhite M, Jackson AW, Morrow JR Jr. The relationship of body mass index, medical costs, and job absenteeism. Am F Health Behav 2003;27:456-462.

10. Thorlacius S, Stefansson SB, Steingrimsdottir L. Prevalence of disability pension related to obesity in Iceland 1992-2004. Laeknabladid 2006;92:525-529.

11. Ells LJ, Lang R, Shield JPH et al. Obesity and disabilitya short review. Obes Rev 2006;7:341-345.

12. Ricci JA, Chee E. Lost productive time associated with excess weight in the U.S. workforce. $\mathcal{F}$ Occup Environ Med 2005;47:1227-1234.

13. Rissanen A, Heliovaara M, Knekt P, Reunanen A, Aromaa A, Maatela J. Risk of disability and mortality due to overweight in a Finnish population. Br Med $\mathcal{f}$ 1990;301: 835-837.

14. Mansson N, Eriksson $\mathrm{K}$, Israelsson $\mathrm{B}$, Ranstam J, Melander A, Rastam L. Body mass index and disability pension in middle-aged men-non-linear relations. Int f Epidemiol 1996;25:80-85.

15. Arena VC, Padiyar KR, Burton WN, Schwerha JJ. The impact of body mass index on short-term disability in the workplace. F Occup Environ Med 2006;48:1118-1124.

16. Kales SN, Polyhronopoulos GN, Aldrich JM, Leitao EO, Christiani DC. Correlates of body mass index in hazardous materials firefighters. F Occup Environ Med 1999;41:589-595.

17. National Fire Protection Association (NFPA 1582): Standard on Comprehensive Occupational Medical Program for Fire Department. Quincy, MA: National Fire Protection Association, 2003.
18. National Fire Protection Association (NFPA 1583): Standard on Health Related Fitness Programs for Firefighters. Quincy, MA: National Fire Protection Association; 2000.

19. Soteriades ES, Hauser R, Kawachi I, Liarokapis D, Christiani DC, Kales SN. Obesity and cardiovascular disease risk factors in firefighters: a prospective cohort study. Obes Res 2005;13:1756-1763.

20. National Heart Lung and Blood Institute. Clinical Guidelines on the Identification, Evaluation, and Treatment of Overweight and Obesity in Adults: The Evidence Report. Bethesda, MD: NHLBI Information Center, 1998.

21. Karpansalo M, Lakka TA, Manninen P, Kauhanen J, Rauramaa R, Salonen JT. Cardiorespiratory fitness and risk of disability pension: a prospective population based study in Finnish men. Occup Environ Med 2003;60:765-769.

22. Kales SN, Soteriades ES, Christoudias SG, Tucker SA, Nicolaou M, Christiani DC. Firefighters' blood pressure and employment status on hazardous materials teams in Massachusetts: a prospective study. $\mathcal{F}$ Occup Environ Med 2002;44:669-676.

23. Karpansalo M, Manninen P, Lakka TA, Kauhanen J, Rauramaa R, Salonen JT. Physical workload and risk of early retirement: prospective population-based study among middle-aged men. f Occup Environ Med 2002;44:930-939.

24. Rimm EB, Stampfer MJ, Giovannucci E et al. Body size and fat distribution as predictors of coronary heart disease among middle-aged and older US men. Am $\mathcal{F}$ Epidemiol 1995;141:1117-1127.

25. Rhea MR, Alvar BA, Gray R. Physical fitness and job performance of firefighters. F Strength Cond Res 2004;18: 348-352.

26. Gallagher D, Visser M, Sepulveda D, Pierson RN, Harris T, Heymsfield SB. How useful is body mass index for comparison of body fatness across age, sex, and ethnic groups? Am F Epidemiol 1996;143:228-239.

27. Ide CW. Failing firefighters: a survey of causes of death and ill-health retirement in serving firefighters in Strathclyde Scotland from1985-94. Occup Med (Lond) 1998;48: 381-388.

28. Wilson MG, Holman PB, Hammock A. A comprehensive review of the effects of worksite health promotion on health-related outcomes. Am $\mathcal{F}$ Health Promot 1996;10: 429-435.

29. Kales SN, Soteriades ES, Christophi CA, Christiani DC. Emergency duties and deaths from heart disease among firefighters in the United States. N Engl F Med 2007;356: 1207-1215.

30. Galuska DA, Will JC, Serdula MK, Ford ES. Are health care professionals advising obese patients to lose weight? f Am Med Assoc 1999;282:1576-1578. 